\title{
Characterization of Chromium-tris(catecholate) Complex: A Theoretical Study
}

Mohammad A. Matin ${ }^{1}$, Mazharul M. Islam² and Mohammed A. Aziz ${ }^{3}$

${ }^{1}$ Centre for Advanced Research in Sciences (CARS), Dhaka University, Dhaka-1000, Bangladesh

${ }^{2}$ Mulliken Center for Theoretical Chemistry, Institut für Physikalische und Theoretische Chemie, Universität Bonn, Beringstraße 4-6, D-53115 Bonn, Germany

${ }^{3}$ Department of Theoretical and Computational Chemistry, Dhaka University, Dhaka-1000, Bangladesh

(Received: 19 October 2016; Accepted: 16 April 2017)

\section{Abstract}

Phenolic compounds generally have special smell and are easily soluble in water, organic solvents (alcohols, esters, chloroform, ethyl acetate) and in alkali. Phenols produce coloured complexes with heavy metal ions, such as with chromium ion. The molecular details underlying the cross-linking mediated by transition metal ions are largely unknown. Using HF/DFT hybrid approach B3LYP, this study examines the structure, binding energy, spectroscopic and electronic properties of complex formed by the attachment of $\mathrm{Cr}^{3+}$ with a catechol ligand. Our study shows that the binding of $\mathrm{Cr}^{3+}$ with the catechol ligand is not as strong as the binding of other metal ions with catechol.The calculated FTIR spectra show strong IR intensities due to large charge polarization. The UV-Vis absorption spectrum of the tris-catecholato- $\mathrm{Cr}^{3+}$ complex shows a clear ligand-to-metal charge transfer. The calculated electronic band gap is $4.06 \mathrm{eV}$ which is in the range of transition metal ion tris-catechol complexes. Thermodynamic properties studied in this work show that the metal ion-ligand binding energy $(532.99 \mathrm{kcal} / \mathrm{mol})$ is close to those of the hexa-aqua complexes (ranging from 540 to $553 \mathrm{kcal} / \mathrm{mol}$ ).

Keywords:Transition metal, catechol, HF/DFT hybrid approach, cross-link, electronic properties, UV-Vis.

\section{Introduction}

Catechol is one of the phenolic compounds known as pyrocatechol or 1,2-dihydroxybenzene with the molecular formula $\mathrm{C}_{6} \mathrm{H}_{4}(\mathrm{OH})_{2}$. This colourless compound occurs naturally in trace amounts. Metal ion-catechol complexes play critical roles in defining the performance of biological materials ${ }^{1}$.

Transition-metal ion complexes with catechols and its derivatives have attracted considerable attention because of their potential use as conductive or magnetic materials ${ }^{2}$ or biologically active compounds ${ }^{3}$. For instance, effective cross-linking strategies are provided between metal ions and catecholic amino acid dopa coordination (3,4dihydroxypheylalanine) in mussel foot protein 1 (mfp-1) chains by the tris-catecholato- $\mathrm{Fe}^{3+}$ complexes in mussel byssus cuticles ${ }^{4-6}$. Coordination complexes form cross-links, when each of the two or more ligands donate a non-bonding electron pair to empty orbitals in a transition metal ion. Because of their high stability and rates of formation, coordination-based cross-links have been proposed to endow certain biological structures with a number of desirable material properties, including triggered self-assembly increased toughness, self-repair, adhesion and high hardness in the absence of mineralization and mechanical tenability. Natural products such as dark chocolate, black tea, coffee, etc. have got many polyphenolic antioxidants. It is well known that these compounds react with free radicals and the product is more stable ${ }^{7}$. They will stop the chain reaction of free radicals and damage DNA and protein which are also important in our body. In some studies related to the biosensor, electrochemical biosensors, membrane, and polymeric materials including the catechol compound have been carried out. One of the most important activities of the catechol is the ability to compose a compound with the iron ions $^{7-8}$. Although catechol is a simple molecule, the complex compound formed by three catechol with $\mathrm{Cr}^{3+}$ (as shown in the Fig. 1) can express different significance ${ }^{9}$. This molecule is well known in the metal-ligand type of the organic compounds and widely used as the color matter in the analytical determination reactions. The structural and spectroscopic properties of the tris-catecholato- $\mathrm{Cr}^{3+}$ complex, which are known to play a central role in many coordination cross-links, were examined ${ }^{10-11}$. Previous computational studies on $\mathrm{Cr}^{3+}$-catecholato complexes include molecular orbital (MO) calculations for the $\left[\mathrm{M}(\mathrm{cat})_{3}\right]^{\mathrm{n}-}$ series $\left(\mathrm{M}=\mathrm{Cr}^{3+}\right.$ or $\mathrm{V}^{3+}$ ) and density functional theory (DFT) calculations for $[\mathrm{Cr}(\operatorname{tren})(3,6-\mathrm{dtbc})]^{+}$and its oxidized analogue ${ }^{12}$. In case of tris-catecholato-metal ion complex, one set of lone pair (one from each $\mathrm{O}$ ) is often delocalized into the p orbital of the structure of the tri-catechol ligands which gives them selectivity to form strong metal-catechol complexes as well as makes them attractive candidates for their applications in pharmaceutical industries ${ }^{13}$. Apart from the structural analysis, the theoretical studies for the characterization of oxidation of chromium states in tris-catechol are rare. For this reason, we have studied the structural, thermodynamic, spectroscopic and electronic properties of the triscatecholato-Cr ${ }^{3+}$ complex using HF/DFT hybrid approach B3LYP.

\section{Computational Method}

We have studied the tris-complex of $\mathrm{Cr}^{3+}$ with catecholate ligand (Fig. 1). All calculations were done by B3LYP method $^{14}$ with the $6-311 \mathrm{G}(\mathrm{d}, \mathrm{p})$ basis sets in gas phase using Gaussian 09 program ${ }^{15}$. GaussView 5.0.8 was used for the visualization of the structure and simulated vibrational spectra. Geometry optimization of individual species ligand, metal and complexes were performed. Geometry optimization was taken to be converged if the maximum atomic force was smaller than 0.00045 Hartree/Bohr. No symmetry was imposed in all the calculations. After optimizing the geometry of the coordination complex, the metal-ligand binding energy was calculated as ${ }^{16}$

$$
\Delta E=-\frac{\left(E_{\text {complex }}-E_{\text {metal }}-E_{\text {ligand }}\right)}{3}
$$


Where $E_{\text {complex }}, E_{\text {metal }}$ and $E_{\text {ligand }}$ are the energies of the triscatecholato- $\mathrm{Cr}^{3+}$ complex, the metal ion and catecholate ligand, respectively. Therefore, $\Delta E$ refers to the binding energy per ligand.

The IR spectra of the tris-catecholato- $\mathrm{Cr}^{3+}$ complex were calculated by performing frequency calculations using the analytic gradient and Hessian. The vibrational frequencies were scaled by a factor of 0.9668 , which produced good agreement with the experiment for a wide range of systems ${ }^{17}$. Electronically excited state calculation was carried out to find the UV-Vis spectra of the tris-catecholato$\mathrm{Cr}^{3+}$ complex. The vertical excitation energies were obtained using the time-dependent DFT(TDDFT) at the level of CAM-B3LYP ${ }^{14} / 6-311+g(d, p)$ where the ground state optimization was done first.

\section{Results and Discussion}

The structural parameters of fully optimized tris-catecholato$\mathrm{Cr}^{3+}$ complex (as shown in Fig. 1) are presented in Table 1. The metal ion and oxygen atoms are $2.02 \AA$ apart on average. The $\mathrm{O}-\mathrm{Cr}^{3+}-\mathrm{O}$ angles are $90.1^{\circ}$ on average, indicating almost octahedral geometry in the coordination. Previous DFT ${ }^{18}$ and X-ray analysis ${ }^{19}$ of the tris-catecholato$\mathrm{Cr}^{3+}$ complex reported $\mathrm{Cr}^{3+}-\mathrm{O}$ distances of 2.04 and $1.980 \AA$, respectively.

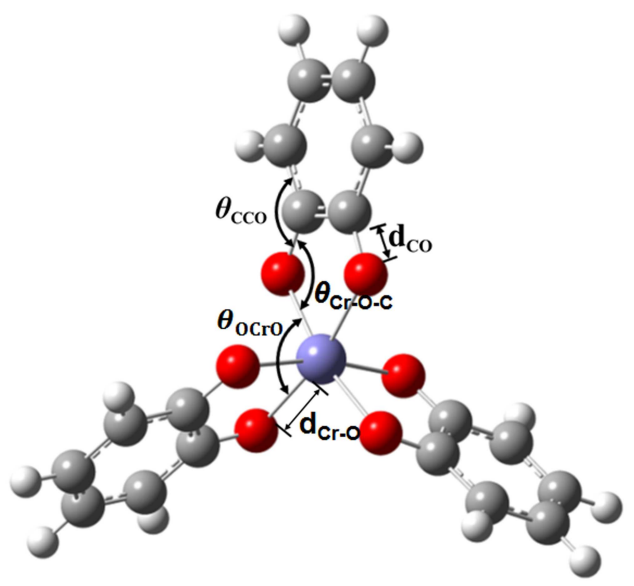

Fig. 1. Metal binding to catechol, optimized geometry of the triscatecholato- $\mathrm{Cr}^{3+}$ complex

The present $\mathrm{Cr}^{3+}-\mathrm{O}$ distances are close to those previously calculated for the hexa-aqua complexes of the metal ions ranging from $\mathrm{Ti}$ to $\mathrm{Fe}^{20}$.

The present $\mathrm{O}-\mathrm{Cr}^{3+}-\mathrm{O}$ angle is significantly larger by $6.5^{\circ}$ than the previous X-ray crystal structure, $83.56^{\circ 21}$. Another DFT study predicted $\mathrm{Cr}^{3+}-\mathrm{O}$ distance and $\mathrm{O}-\mathrm{Cr}-\mathrm{O}$ angle as $1.934 \AA$ and $81.41^{\circ}$ respectively ${ }^{22}$.

Table 1 shows the average and standard deviations of the chromium-oxygen distances, $\left(d_{C r-O} s\right)$, carbon-oxygen distances $\left(d_{C-O} ' s\right)$ and the angles of $\mathrm{O}-\mathrm{Cr}^{3+}-\mathrm{O}$ triplets, $\left(\theta_{O-C r-O}{ }^{\prime} s\right)$, the angles of C-C-O triplets, $\theta_{C-C-O} ' s$ and
Cr-O-C, $\left(\theta_{C r-O-C} s\right)$. All the $\mathrm{O}-\mathrm{Cr}^{3+}-\mathrm{O}$ angles, however, fluctuate significantly from their average values of approximately $90^{\circ}$. The present $d_{C r^{3+}-O}$ is close to those previously calculated for the hexa-aqua complexes of the metal ions ranging from $\mathrm{Ti}$ to $\mathrm{Fe}^{20}$.

Calculated IR spectrum of the tris-catecholato- $\mathrm{Cr}^{3+}$ complex is shown in the Figure 2. Two intense peaks have appeared at 1260 and $1476 \mathrm{~cm}^{-1}$. Each of these two major peaks has originated from an in-plane deformation mode involving the $\mathrm{C}-\mathrm{C}$ and $\mathrm{C}-\mathrm{O}$ stretching and the $\mathrm{C}-\mathrm{H}$ bending of catecholate. Only two out of three catecholate groups are actively involved in these modes of vibration.

Table 1. Geometric parameters of the tris-catecholato$\mathrm{Cr}^{3+}$ complex. The average values are listed with the standard deviations in parentheses.

\begin{tabular}{ccc}
\hline & $\begin{array}{c}\text { Calculated values } \\
\text { (present work) }\end{array}$ & $\begin{array}{c}\text { Experimental }^{21} \\
\text { values }^{21}\end{array}$ \\
\hline$d_{C r^{3+}-O}(\AA)$ & $2.02( \pm 0.00)$ & 1.986 \\
$d_{C-O}(\AA)$ & $1.31( \pm 0.00)$ & 1.349 \\
$\theta_{O-C r^{3+}-O}\left(^{\circ}\right)$ & $90.1( \pm 5.60)$ & 83.6 \\
$\theta_{C-C-O}\left(^{\circ}\right)$ & $125.04( \pm 0.01)$ & 123.4 \\
$\theta_{C r^{3+}-O-C}\left({ }^{\circ}\right)$ & $113.09( \pm 0.01)$ & 110.7 \\
\hline
\end{tabular}

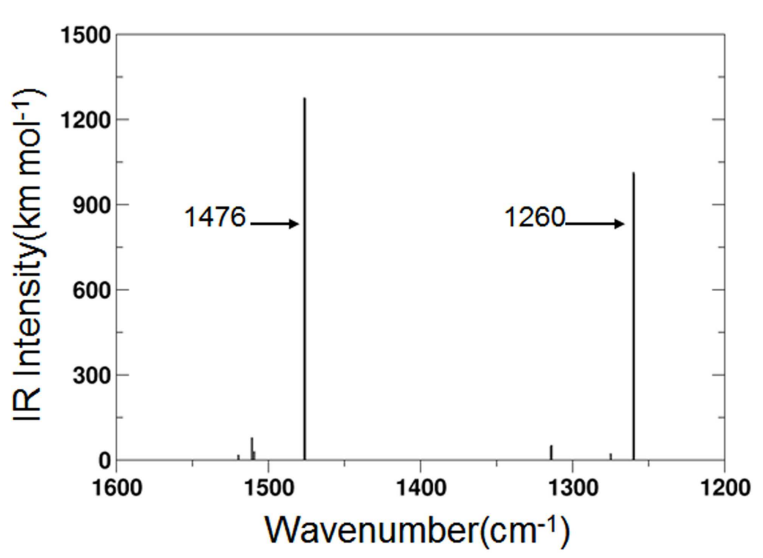

Fig. 2. IR spectrum of the tris-catecholato- $\mathrm{Cr}^{3+}$ complex. The two strongest peaks are indicated by the arrows.

The vibrational mode with a frequency of $1470 \mathrm{~cm}^{-1}$ has exhibited prominent $\mathrm{C}-\mathrm{H}$ bending. These two major IR peaks are close to those previously observed for tris (3,5-di-t-butylo-semiquinato)chromium(III) at 1265 and $1470 \mathrm{~cm}^{-1}$, and 1258 and $1485 \mathrm{~cm}^{-1}$ for Mytilus edulis foot protein ( Mefp-1) on the iron substrate ${ }^{23-24}$

The high intensities of IR peaks obtained in this work arise from the greater charge polarization due to the highly positive $\mathrm{Cr}^{3+}$ being surrounded by three negatively charged catecholate ligands. Because of the charge polarization, the vibrations result in unsymmetrical distortions of the complex which induce large dipole moment changes and large IR intensities. 
Fig. 3 shows the UV-Vis absorption spectrum of the triscatecholato- $\mathrm{Cr}^{3+}$ complex. The absorption maximum is found at $610 \mathrm{~nm}$, agrees well with the experimental value $592 \mathrm{~nm}$ found for tris-catecholateo- $\mathrm{Cr}^{3+3-9}$.

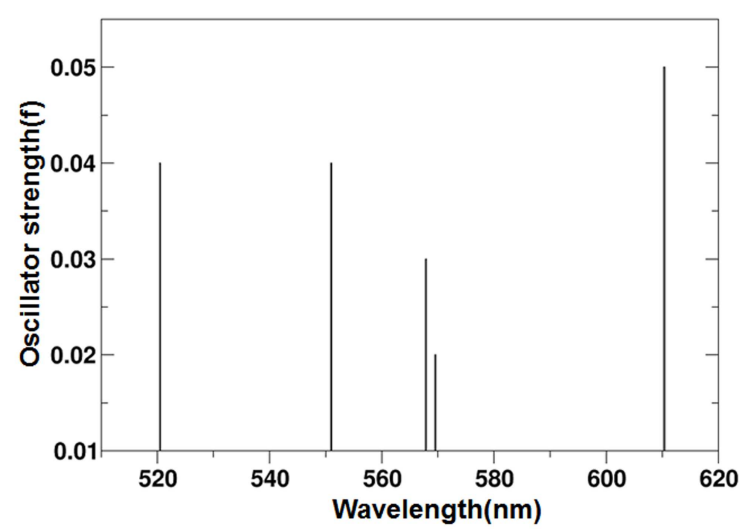

Fig. 3. UV-vis spectrum of the tris-catecholato- $\mathrm{Cr}^{3+}$ complex obtained from the present calculation.

To characterize the electronic transitions, two frontier molecular orbitals (MOs) are illustrated in the figure 4, ranging from the highest occupied MO-1 (HOMO-1) to the highest occupied MO (HOMO). The absorption maximum at $610 \mathrm{~nm}$ originated predominantly from the HOMO to LUMO transition. In the HOMO, the electron density is distributed mainly over three catecholate ligands. Therefore, the strongest peak in the UV-Vis spectrum has originated clearly from ligand-to-metal charge transfer. Strong metal ligand delocalization is found to occur between two of the three ligands in each case.

The predominant bonding nature of the orbitals is $\pi$ antibonding with respect to both $\mathrm{Cr}^{3+}-\mathrm{O}$ and $\mathrm{C}-\mathrm{O}$ for one ligand. An electronic system with a larger HOMO-LUMO gap should be less reactive than one having a smaller gap. The HOMO-LUMO gap of this complex is $4.06 \mathrm{eV}$ (Table 2). (a)

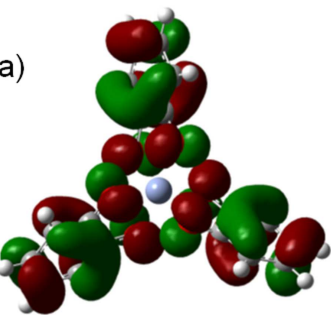

(b)

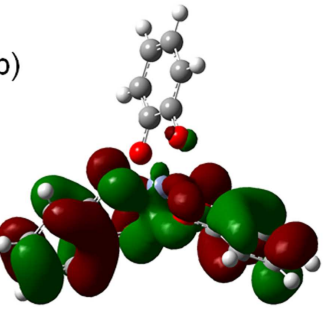

Fig. 4. Frontier MOs (a) HOMO and (b) HOMO-1 of the triscatecholato- $\mathrm{Cr}^{3+}$ complex. The $\mathrm{H}, \mathrm{C}$, and $\mathrm{O}$ atoms are shown as white, gray, and red spheres, respectively. The orbital lobes shown in green and red represent the opposite phases.

The charge on the metal ion is presented in the Table 2. Four different schemes are used to calculate the charge: natural population analysis (NPA) ${ }^{25}$, Merz-Singh-Kollman scheme (MK) ${ }^{26}$, CHarges from Electrostatic Potentials with grid oriented $(\mathrm{CHelpG})^{27}$ and CHarges from Electrostatic
Potentials $(\mathrm{CHelp})^{28}$ methods. The charge varied according to the scheme. For example, NPA gave a charge of 1.687 for $\mathrm{Cr}$, but the charge was found 1.385 if the MK scheme was used $^{26}$. However, the present trend of the charge deviates considerably from a uniform decrease with different scheme, as found for the hexa-aqua complexes ${ }^{20}$.

Table 2. The electronic structure parameters, atomic charges on the metal atom at various charge schemes, NPA, MK, CHelpG and CHelp and binding energy calculated for the tris-catecholato- $\mathrm{Cr}^{3+}$ complex.

\begin{tabular}{lll}
\hline$\Delta E_{\text {gap }}(\mathrm{eV})$ & Atomic charge & $\Delta \mathrm{E}(\mathrm{kcal} / \mathrm{mol})$ \\
\hline 4.06 & $1.687(\mathrm{NPA})$ & $532.99(553.41)^{\mathrm{a}}$ \\
& $1.385(\mathrm{MK})$ & \\
& $1.672(\mathrm{CHelpG})$ & \\
& $1.884(\mathrm{CHelp})$ &
\end{tabular}

NPA $=$ Natural Population Analysis ${ }^{25}$

MK = Merz-Singh-Kollman scheme ${ }^{26}$.

$\mathrm{CHelpG}=\mathrm{CHarges}$ from Electrostatic Potentials with grid oriented $^{27}$.

CHelp $=$ CHarges from Electrostatic Potentials ${ }^{28}$

${ }^{a}$ The binding energy previously calculated for the hexaaqua complex ${ }^{20}$.

We have investigated the metal-ligand binding energy of the trivalent $\mathrm{Cr}$ ion. Table 2 shows that the present $\Delta E$ value greatly exceeds the typical physisorption energy of a catechol molecule on a metallic surface. Lee et al. reported that a single catechol molecule binds to a titanium surface with a binding energy of $22.2 \mathrm{kcal} / \mathrm{mol}^{29}$. A similar value of energy was reported by a DFT study of the adsorption of DOPA to titanium oxide $(25-30 \mathrm{kcal} / \mathrm{mol})^{30}$. The present binding energy $(532.99 \mathrm{kcal} / \mathrm{mol})$ is much larger than these but very close to those of the hexa-aqua complexes (ranging from 540.05 to $553.41 \mathrm{kcal} / \mathrm{mol})^{20}$.

We have also investigated the solvent effects for the $\mathrm{Cr}^{3+}$ complex by employing the conductor-like polarizable continuum model ${ }^{31-32}$. The energy of metal complex is virtually unchanged in a water solvent, only varying by less than $0.024 \%$ (Table 3 ). The structural change of the complex due to the presence of the solvent was not considered in this calculation. We, however expect that the near octahedral geometry around the central metal ion of the complex remains intact with the introduction of the solvent Therefore, the present metal-ligand binding energy presumably will not deviate much from those in the solvent. A systematic study on the solvent effects is reported elsewhere ${ }^{33}$. We have calculated the zero-point energy (ZPEs), thermal energy, enthalpy, entropy, Gibbs free energy and dipole moment for the complex and presented in Table 4. 
Table 3. Solvent effect of trivalent transition metal complex.

\begin{tabular}{|l|l|l|l|l|}
\hline Metal complex & $\begin{array}{l}\text { Electronic energy } \\
\text { (gas phase opt) } \\
\text { (a.u.) }\end{array}$ & $\begin{array}{l}\text { Electronic energy (sol. phase, } \\
\text { gas phase optimized geometry } \\
\text { was taken) (a.u.) }\end{array}$ & $\begin{array}{l}\text { Solvent effect } \\
\text { (kcal/mol) }\end{array}$ & $\begin{array}{l}\% \text { Relative } \\
\text { deviation }\end{array}$ \\
\hline $\mathrm{Cr}^{3+}$ & -2189.3064 & -2189.8262 & -326.19 & 0.024 \\
\hline
\end{tabular}

Table 4. Zero-point vibrational energies (kcal/mol), rotational constants (GHz), entropies (cal/mol K) and dipole moment (D) for the complex (calculations performed with B3LYP/6-311g(d,p)).

\begin{tabular}{cc}
\hline Zero-point vibrational energy $(\mathrm{kcal} / \mathrm{mol})$ & 158.78 \\
\hline Rotational constants/GHz & 0.20978 \\
Dipole moment/Debye & 0.20917 \\
& 0.11928 \\
& 0.00570 \\
E (Thermal) $(\mathrm{kcal} / \mathrm{mol})$ & 171.871 \\
$\mathrm{CV}(\mathrm{cal} / \mathrm{mol} \mathrm{K})$ & 84.591 \\
Entropy (cal/mol K) & 152.845 \\
Sum of electronic and thermal enthalpies (a.u.) & -2189.3064 \\
\hline
\end{tabular}

\section{Conclusion}

A complete description of the geometrical parameters, spectroscopic, electronic and thermal properties of the triscatecholato- $\mathrm{Cr}^{3+}$ complex was performed theoretically. The present work will be helpful to understand the structure of the tris-catecholato- $\mathrm{Cr}^{3+}$ for studying the structure-activity relationship. The optimized bond distances and bond angles are in well accord with the available experimental data. The simulated IR and UV-vis spectra of the tris-catecholato$\mathrm{Cr}^{3+}$ complex are all consistent with the previous measurements and calculations. The binding energy of transition-metal ion coordinating to the catechol ligands are calculated. The metal-ligand binding energy is at least 1 order of larger than that of the metal-surface physisorption.

\section{References}

1. Xu, Z., 2013. Mechanics of Metal-Catecholate Complexes: The Roles of Coordination State and Metal Types. Scientific Reports. 3, 2914.

2. Chang, H.-C., H. Miyasaka, and S. Kitagawa, 2001. New Molecular Assemblies of Redox Isomers, [Criii $(\mathrm{X} 4 \mathrm{sq})_{3^{-}}$ $\mathrm{N}(\mathrm{X} 4 \mathrm{cat}) \mathrm{N}]-\mathrm{N}(\mathrm{X}=\mathrm{Cl}$ and $\mathrm{Br} ; \mathrm{N}=0,1$, and 2), with Metallocenium Cations, [Miiicp2] ${ }^{+}(\mathrm{M}=\mathrm{Co}$ and $\mathrm{Fe})$ : X-Ray Metallocenium Cations, [Miiicp2 $]^{+}(\mathrm{M}=\mathrm{Co}$ and Fe $)$ : X-Ray
Crystal Structures and Physical Properties. Inorg. Chem. 40, Crystal S
$146-156$.

3. Isied, S. S., G. Kuo, and K. N. Raymond, 1976. Coordination Isomers of Biological Iron Transport Compounds. V. The Preparation and Chirality of the Chromium (III) Enterobactin Preparation and Chirality of the Chromium (III) Enterobactin
Complex and Model Tris(Catechol)Chromium(III) Analogues. Complex and Model Tris(Catecho

4. Harrington, M. J., A. Masic, N. Holten-Andersen, J. H. Waite, P. Fratzl, 2010. Iron-Clad Fibers: A Metal-Based Biological Strategy for Hard Flexible Coatings. Science, 328, 216-220.

5. Politi, Y., M. Priewasser, E. Pippel, P. Zaslansky, J. Hartmann, S. Siegel, C. Li, F.G. Barth, P. Fratzl, 2012. A Spider's Fang: How to Design an Injection Needle Using
Chitin-Based Composite Material. Adv. Funct. Mater., 22, 2519-2528.

6. Zeng, H., D. S. Hwang, J. N. Israelachvili, and J. H. Waite, 2010. Strong Reversible $\mathrm{Fe}^{3+}$-Mediated Bridging between Dopa-Containing Protein Films in Water. Proc. Natl. Acad. Sci. 107, 12850-12853.

7. Ferreras, J. A. J. -S. Ryu, F. Di Lello, D. S. Tan, and L. E. N. Quadri, 2005. Small-Molecule Inhibition of Siderophore Biosynthesis in Mycobacterium Tuberculosis and Yersinia Pestis. Nat. Chem. Biol. 1, 29-32.

8. Garcia, C. R., C. Angele-Martinez, J. A. Wilkes, H. C. Wang, E. E. Battin, J. L. Brumaghim, 2012. Prevention of Iron- and Copper-Mediated DNA Damage by Catecholamine and Amino Acid Neurotransmitters, L-Dopa, and Curcumin: Metal Amino Acid Neurotransmitters, L-Dopa, and Curcumin: Metal
Binding as a General Antioxidant Mechanism. Dalton Trans., Binding as a Gene.

9. Sever, M. J., and J. J. Wilker, 2004. Visible Absorption Spectra of Metal-Catecholate and Metal-Tironate Complexes. Dalton Trans. 1061-1072.

10. Levina, A., G. J. Foran, D. I. Pattison, and P. A. Lay, 2004 X-Ray Absorption Spectroscopic and Electrochemical Studies of Tris (Catecholato(2-)) Chromate (V/IV/III) Complexes. Angew. Chem. Int. Ed. 43, 462-465.

11. Wheeler, D. E., and J. K. McCusker, 1998. Electron Exchange and the Photophysics of Metal-Quinone Complexes. 1 Synthesis and Spectroscopy of Chromium-Quinone Dyads. Inorg. Chem. 37, 2296-2307.

12. Rodriguez, J. H., D. E. Wheeler, J. K. McCusker , 1998 Density Functional Studies of a Heisenberg Spin Coupled Chromium-Semiquinone Complex and Its ChromiumChromium-Semiquinone Complex and Its Chrom
Catechol Analog. J. Am. Chem. Soc., 120, 12051-12068.

13. Chandra, A., and T. Uchimaru, 2002. The O-H Bond Dissociation Energies of Substituted Phenols and Proton Affinities of Substituted Phenoxide Ions: A Dft Study. Int. J. Mol. Scien. 3, 407.0020

14. Becke, A. D., 1993. Density-Functional Thermochemistry. III The Role of Exact Exchange. J. Chem. Phys. 98, 5648-5652. 
15. Frisch M. J., G.W. Trucks, H.B. Schlegel, G.E. Scuseria, M.A. Robb, J.R. Cheeseman, G. Scalmani, V. Barone, B. Mennucci, G.A. Petersson, H. Nakatsuji, M. Caricato, X. Li, H.P. Hratchian, A.F Izmaylov, J. Bloino, G. Zheng, J.L. Sonnenberg, M. Hada, M. Ehara, K. Toyota, R. Fukuda, J. Hasegawa, M. Ishida, T. Nakajima, Y. Honda, O. Kitao, H. Nakai, T. Vreven, J.A. Montgomery Jr., J.E. Peralta, F. Ogliaro, M. Bearpark, J.J. Heyd, E. Brothers, K.N. Kudin, V.N. Staroverov, R. Kobayashi, J. Normand, K. Raghavachari, A. Rendell, J.C. Burant, S.S. Iyengar, J. Tomasi, M. Cossi, N. Rega, N.J. Millam, M. Klene, J.E. Knox, J.B. Cross, V. Bakken, C. Adamo, J. Jaramillo, R. Gomperts, R.E. Stratmann, O. Yazyev, A.J. Austin, R. Cammi, C. Pomelli, J.W. Ochterski, R.L. Martin, K. Morokuma, V.G. Zakrze. wski, G.A. Voth, P. Salvador, J.J. Dannenberg, S. Dapprich, A.D. Daniels, O. Farkas, J.B. Foresman, J.V. Ortiz, J. Cioslowski, D.J Fox, Gaussian, Inc., Wallingford CT, 2010.

16. Myradalyyev, S., T. Limpanuparb, X. Wang, and H. Hirao, 2013. Comparative Computational Analysis of Binding Energies between Several Divalent First-Row Transition Metals $\left(\mathrm{Cr}^{2+}, \mathrm{Mn}^{2+}, \mathrm{Fe}^{2+}, \mathrm{Co}^{2+}, \mathrm{Ni}^{2+}\right.$, and $\left.\mathrm{Cu}^{2+}\right)$ and Ligands (Porphine, Corrin, and Tmc). Polyhedron, 52, 96-101.

17. Merrick, J. P., D. Moran, and L. Radom, 2007. An Evaluation of Harmonic Vibrational Frequency Scale Factors. J. Phys. Chem. A , 111, 11683-11700.

18. Milsmann, C., A. Levina, H. H. Harris, G. J. Foran, P. Turner, and P. A. Lay, 2006. Charge Distribution in Chromium and Vanadium Catecholato Complexes: X-Ray Absorption Spectroscopic and Computational Studies. Inorg. Chem. 45, 4743-4754.

19. Wood, R. M., K. A. Abboud, R. C. Palenik, and G. J. Palenik, 2000. Bond Valence Sums in Coordination Chemistry. Calculation of the Oxidation State of Chromium in Complexes Containing Only $\mathrm{Cr}-\mathrm{O}$ Bonds and a Redetermination of the Crystal Structure of Potassium Tetra(Peroxo)Chromate(V). Inorg. Chem. 39, 2065-2068.

20. Aakesson, R., L. G. M. Pettersson, M. Sandstroem, and U. Wahlgren, 1994. Ligand Field Effects in the Hydrated Divalent and Trivalent Metal Ions of the First and Second Transition Periods. J. Am. Chem. Soc. 116, 8691-8704.

21. Raymond, K. N., S. S. Isied, L. D. Brown, F. R. Fronczek, and J. H. Nibert, 1976. Coordination Isomers of Biological Iron Transport Compounds. Vi. Models of the Enterobactin Coordination Site. A Crystal Field Effect in the Structure of Potassium Tris (Catecholato) Chromate (III) and -Ferrate (III) Sesquihydrates, $\mathrm{K}_{3}\left[\mathrm{M}\left(\mathrm{O}_{2} \mathrm{C}_{6} \mathrm{H}_{4}\right)_{3}\right]$.Cntdot.1.5h2o, M = Chromium, Iron. J. Am. Chem. Soc. 98, 1767-1774.
22. Kapre, R. R., E. Bothe, T. Weyhermüller, S. DeBeer George, N. Muresan, and K. Wieghardt, 2007. Electronic Structures of Tris(Dioxolene)Chromium and Tris(Dithiolene)Chromium Complexes of the Electron-Transfer Series $\left[\mathrm{Cr}(\text { Dioxolene })_{3}\right] \mathrm{Z}$ Complexes of the Electron-Transfer Series $\left.[\mathrm{Cr} \text { (Dioxolene })_{3}\right] \mathrm{Z}$
and $\left[\mathrm{Cr}(\text { Dithiolene })_{3}\right] \mathrm{Z}(\mathrm{Z}=0,1-, 2-, 3-)$. A Combined Experimental and Density Functional Theoretical Study. Inorg. Chem. 46, 7827-7839

23. Brown Dennis, G., and W. L. Johnson, 1979. Preparation and Properties of Two Tris O-Semiquinone Complexes. In $Z$ Naturforsch. B, 34, 712 .

24. Zhang, F., M. Sababi, T. Brinck, D. Persson, J. Pan, and P. M. Claesson, 2013. In Situ Investigations of $\mathrm{Fe}^{3+}$ Induced Complexation of Adsorbed Mefp-1 Protein Film on Iron Substrate. J. Colloid Interface Sci. 404, 62-71.

25. Reed, A. E., R. B. Weinstock, and F. Weinhold, 1985. Natural Population Analysis. J. Chem. Phys. 83, 735-746.

26. Singh, U. C., and P. A. Kollman, 1984. An Approach to Computing Electrostatic Charges for Molecules. J. Comput. Chem. 5, 129-145.

27. Breneman, C. M., and K. B. Wiberg, 1990. Determining Atom-Centered Monopoles from Molecular Electrostatic Potentials. The Need for High Sampling Density in Formamide Conformational Analysis. J. Comput. Chem. 11, 361-373.

28. Chirlian, L. E., and M. M. Francl, 1987. Atomic Charges Derived from Electrostatic Potentials: A Detailed Study. J. Comput. Chem. 8, 894-905.

29. Lee, H., N. F. Scherer, and P. B. Messersmith, 2006. SingleMolecule Mechanics of Mussel Adhesion. Proc. Natl. Acad. Sci. 103, 12999-13003.

30. Vega-Arroyo, M., P. R. LeBreton, T. Rajh, P. Zapol, and L. A. Curtiss, 2005. Density Functional Study of the $\mathrm{TiO}_{2-}$ Dopamine Complex. Chem. Phys. Lett. 406, 306-311.

31. Barone, V., and M. Cossi, 1998. Quantum Calculation of Molecular Energies and Energy Gradients in Soluti on by a Conductor Solvent Model. J. Phys. Chem. A 102, 1995-2001.

32. Tomasi, J., B. Mennucci, and R. Cammi, 2005. Quantum Mechanical Continuum Solvation Models. Chem. Rev. 105 2999-3094.

33. Matin, M. A., M. M. Islam, T, Bredow, and M. A. Aziz, 2017. The Effects of Oxidation States, Spin States and Solvents on Molecular Structure, Stability and Spectroscopic Properties of Fe-Catechol Complexes: A Theoretical Study. Advances in Chemical Engineering and Science, 7,137-15. 
